\title{
A Review of the Potential of Natural Gas in Energy Sector Reforms: Case Study Nigeria
}

\author{
${ }^{1}$ Alhassan Musa Obi, ${ }^{1}$ Abdulmalik Ibrahim Umar, ${ }^{2}$ Ismaila Yusuf Pindiga \\ ${ }^{1}$ Mineral \& Petroleum Resources Engineering Department \\ ${ }^{2}$ Electrical \& Electronic Engineering Department \\ Kaduna Polytechnic, Nigeria
}

\begin{abstract}
This paper review the potential of natural gas in power reforms in Nigeria. The study reveals that, with almost 140 trillion cubic feet of gas, Nigeria ranks as the $7^{\text {th }}$ holder of proven gas reserves in the world and largest in Africa. In energy terms, the reserve of natural gas in Nigeria is at least of the same order as the reserves of the crude oil. About 1000 standard cubic feet of gas is produced in Nigeria in association with a barrel of oil. Therefore, averagely with oil production of 2.2 million barrels per day, about 2.2 billion standard cubic feet of associated gas is produced. Nigeria has not sufficiently explored non associated gas yet, as such, gas reserves are most likely to increase over time and consequently exceed our foreseeable needs. Coal being another source of gas suffers due to its environmental associated hazards (acid rain, gas explosion) and low calorific value. Nuclear energy results in nuclear accidents, hydroelectric power is capital intensive and occupies vast acres of land that could be utilized for agricultural purposes and generates low output. Kainji, Shiroro \& Jebba hydroelectric power plants have a combined power output of $1350 \mathrm{mw}$ with a work force of over 3000 . Natural gas is a nontoxic, clean source of energy, having a high calorific value and proven to be a more attractive alternative in the energy sector and contributes over $60 \%$ of the total output of the national grid.
\end{abstract}

Keyword: Natural Gas, Associated Gas, Non Associated Gas, Power, Reforms.

\section{INTRODUCTION}

Energy has a major impact on every aspect of our socioeconomic life. It plays a vital role in the economic, social and political development of our nation. Inadequate supply of energy restricts socio-economic activities, limits economic growth and adversely affects the quality of life. Improvements in standards of living are manifested in increased food production, increased industrial output, the provision of efficient transportation, adequate shelter, healthcare and other human services. These will require increased energy consumption. Thus, our future energy requirements will continue to grow with increase in living standards, industrialization and a host of other socioeconomic factors ${ }^{[1]}$.

As the very basis of development, energy use is closely related to the level of productivity in the industry, commerce, agriculture and even in office activities. Energy consumption per capita is one of the indicators or benchmarks for measuring the standard of living of a people or nation. The unprecedented use of energy which began with the industrial revolution certainly brought about massive increase in productivity and change in lifestyle.
Since then energy demand has been in the increase- to produce more products, travel further and faster or to be more comfortable. Physically, energy is defined as the capacity for doing work. The capacities of energy to do work are inherent properties of energy carriers. Although energy cannot be created nor destroyed according to classical thermodynamics, its capacity for doing work can be degraded and destroyed due to system irreversibility in line with the logic of the second law of thermodynamics ${ }^{[2]}$.

Some of the common energy carriers or sources are coal, petroleum, natural gas, nuclear fuels, biomass etc. Of all these, the most widely used energy sources are the hydrocarbon compounds or fossil fuels which account for more than $80 \%$ of global primary energy consumption ${ }^{[3]}$. For instance, fossil energies provide about $67 \%$ of the energy needed to produce electricity - a veritable and the most terminal form of energy for transmission and distribution for industrial production processes ${ }^{[4]}$. Energy usage has become an important concern in the past years and there has been growth awareness and an increase in taking personal responsibilities in preventing environmental pollution by minimizing energy waste. Energy has been the key to economic development worldwide, but in the way it is sourced, produced and used, two major drawbacks have emerged. First, the overall energy system has been very inefficient. And second, major environmental and social problems, both local and global, have been associated with the energy system ${ }^{[5]}$. Climate change and environmental externalities associated with energy consumption have become a major international issue. It has been observed that among the various sectors contributing to green house gas (GHG) emissions, industrial sector contribution was significant; thus mitigating GHG emissions from the sector offers one of the best ways of confronting the climate change problem. Energy efficiency is a major key in this regard. An estimated $10-30 \%$ reduction can be achieved at little or no cost by improving efficiency of energy use in the industry ${ }^{[6]}$. Although Nigeria is relatively endowed with abundant fossil fuels and other renewable energy sources, the energy situation in the country is yet to be structured and managed in such a way as to ensure sustainable energy development, most especially in the industrial sector. Nigeria as a nation is passing through a serious energy crisis and it has been even more affected not by a lack of energy resources, but largely due to poor resource and financial management, a crippling dependence on imports particularly second-hand goods built with out-dated, inefficient technology etc ${ }^{[7]}$. As 
a nation that has limited technological capacity but sees industrialization as constituting a crucial leverage and precondition for meaningful development, Nigeria should be wise enough to manage her scarce energy resources judiciously.

The use of energy pervades every aspect of modern society but it is not efficiently used in many industries. In view of the fact that there is an incessant increase in fuel costs, energy efficiency studies are thus rapidly becoming more important. Several millions of dollar can be saved in accumulated energy cost when energy is properly managed. Based on this fact, several researchers have reported on the energy consumption, conservation potential and environmental impact of energy use of different industrial process operations both within and outside Nigeria. Nagesha ${ }^{[8]}$ presented the energy consumption pattern in a textile dyeing industrial cluster and environmental implications in terms of emission of GHGs due to energy use. The study identified substantial scope for energy efficiency and analysed energy consumption in the cluster from an economic perspective. All the economic performance indicators adopted in the study seemed to have significant association with energy efficiency in the cluster. Also, it was observed that the small scale industries which are energy efficient performed better on the economic front and experienced 'higher returns to scale'. The study concluded that the firms in the energy intensive product clusters must aim at enhancing their energy efficiency as it leads to multiple benefits and ensures sustainable development in the long run. Fawkes, investigated energy efficiency in South African Industry. This study showed that strong incentives exist for energy efficiency improvement in South African industry, in particular, the potential for increasing profit, the need to reduce greenhouse gas (GHG) emissions, the need to maintain economic competitiveness, and the need to delay the cost of new peak-load electricity generation facilities. In their study, Lung et al, investigated the impacts that several emerging technologies have had in the U.S food processing industry. This paper assessed the energy efficiency potential for four of these technologies in the U.S. food processing industry. Based on the assessments of these four emerging and newly commercialized technologies, the potential for energy savings in the U.S. food industry is quite strong. In addition, these technologies have yielded important productivity and other benefits. Depending on the available market portions in which these technologies can be implemented, sector-wide energy savings could range from $1572 \mathrm{GJ}$ and 134 million $\mathrm{kWh}$ to 2342 GJ and 186 million kWh. In addition, non-energy benefits such as improved product quality, better production and reduced greenhouse gas emissions are likely. To assessed the energy efficiency in Nigerian Eagle Flour Mills Limited, Ibadan. The study which is limited based on the available years of data collected (1996-2000) analyzed the energy consumption, productivity and efficiency of the company. The results of the study showed that energy is not quite efficiently utilized in this industry because the energy productivity increased substantially from $0.369 \mathrm{MJkg}^{-1}$ in 1996 to $0.716 \mathrm{MJkg}^{-1}$ in the year 2000. An average of $47,810.59 \mathrm{GJ}$ of energy was consumed annually within this period with $44.68 \%, 0.23 \%, 42.16 \%$ and $12.93 \%$ of this energy accruing from electricity, lubricants, diesel and petrol, respectively. The average energy productivity, the average intensity of energy and the average cost of energy input per unit $\mathrm{kg}$ are $0.527 \mathrm{MJkg}^{-1}, 1.084 \mathrm{GJm}^{-2}$ and 28 $\mathrm{kobo} / \mathrm{kg}$, respectively. The average value of the normalized performance indicator (NPI) obtained is $0.199 \mathrm{GJm}^{-2}$ which indicates substantial energy consumption for the building type. The areas where the industry uses and wastes energy, and where actions for energy conservation can be implemented were identified.

Aderemi, et al, examined the pattern of energy consumption in selected food companies in South-western Nigeria; identified the sources of electrical energy waste and assessed the effectiveness of the strategies for electrical energy savings in the industry. Four sub-sectors of food and drinks industry in the category of Small and Medium Enterprises were examined. They include; beverage, bakery and confectionery, grain mills and storage of cold food products. The study revealed that the pattern of electrical energy consumption in the food companies was mainly from generating set; this was due to either low voltage or epileptic power supply from national grid. Also, the study identified 12 direct sources that lead to electrical energy waste and inefficient energy utilization in the food industry. One of these, among others was the energy loss as a result of worn out or slack / misaligned belts that needed timely replacement or tensioning. Other indirect sources identified include lack of training and retraining of staff, power factor of electrical equipment, and equipment age, among others. A study carried out a comprehensive energy audit of Vitamalt Nigeria Plc, Agbara using portable thermal and electrical instruments with the objective of studying the pattern of energy consumption and identifying the possibilities of saving energy in the plant. A five year (20002004) data on energy consumption of Vitamalt Nig. Plc was collected and analysed. The study showed that the Normalized performance indicator (NPI) calculated over the span of five years gave an average of $1.2 \mathrm{GJ} / \mathrm{m}^{2}$ indicating a fair range in energy performance level classification (1.0 1.2) while significant savings and improvement in energy usage is achievable. The authors concluded that maximizing efficiency of existing system, optimizing energy input requirement and significant capital investment in procuring new energy conserving equipment must be made for the energy performance level to fall into a good range classification (less than 0.8 ).

The increasing role of energy efficiency as a catalyst for sustainable industrial development is realism in the industrialized countries of the world. In Nigeria the story is different at the moment as the huge benefits derivable from adoption of energy efficiency and conservation measures by industries remain largely untapped due largely to lack of awareness of the economic and social benefits of energy efficiency measures. This, in addition to high incidence of power outages resulting to large scale use of own power generation and lack of investment capital have given rise to high specific energy content of goods produced by industries in Nigeria. The cumulative effect is loss of competitive edge in the global market by these industries and low after- tax 
returns. This constitutes a major disincentive to investment and sustainable industrial growth. As a matter of utmost importance, industries in Nigeria should take advantage of opportunities in low level, low risk but high worth energy efficient measures that reduces the bottom line of any business enterprise. In so doing, a lead time will be created to pursue high-tech driven production processes that will find support at maturity in an already established energy efficient culture.

As earlier presented of the previous works on energy efficiency in Nigerian industries, none of these researchers discussed possible ways of achieving sustainable development in Nigeria in perspective of effective utilization of energy in manufacturing industries in the country. Therefore, the prime objectives of this paper are (i) to review energy consumption pattern in Nigeria (ii) to explore the potential sources to increase energy efficiency in industrial sector in Nigeria and (iii) to explore the role of industrial energy use in achieving sustainable development in Nigeria.

\section{ENERGY SITUATION IN NIGERIA}

Nigeria has an abundant supply of natural energy sources, both fossil and renewable. Energy plays a double role in Nigeria's economy: as an input into all economic activities and as the mainstay of Nigeria's foreign exchange earnings through the export of crude oil and, more recently, from increasing natural gas exports. Nigeria's economy is heavily dependent on the oil sector and now on gas too, since both together account for $90-95 \%$ of export revenues, over $90 \%$ of foreign exchange earnings and nearly $80 \%$ of government revenues. The majority of Nigeria's exports of crude are destined for markets in the United States and Western Europe with Asia becoming an increasingly important market of late.

The National energy is at present almost entirely dependent on fossil fuels and firewood which are depleting fast. According to Chendo, recent estimates indicated that the reserve for crude oil stood at about 23 billion barrels in 1998, natural gas 4293 billion $\mathrm{m}^{3}$ at the beginning of 1999 , made up of $53 \%$ associated gas and $47 \%$ non associated gas. Coal and lignite stood at 2.7 billion tones, Tar sands at 31 billion barrels of oil equivalent and large-scale hydropower at 10,000 MW. Table 1 show various conventional and nonconventional energy sources and their estimated reserves in Nigeria.

Table 1. Nigeria's conventional energy resources

\begin{tabular}{|cccc|}
\hline Resources & Reserve & Resources in Energy units (billion tonnes) & \%Total conventional energy \\
\hline Crude oil & 23 billion barrels & 3.128 & 21.0 \\
Natural gas & 4293 billion m $^{3}$ & 3.679 & 24.8 \\
Coal and lignite & 2.7 billion tonnes & 1.882 & 12.7 \\
Tar sands & 31 billion barrels of Oil equivalent & 4.216 & 28.4 \\
Hydropower & $10,000 \mathrm{MW}$ & $1.954(100 \mathrm{yrs})$ & 13.1 \\
Total & Conventional Commercial Energy resources & 14.859 & $100 \%$ \\
\cline { 3 - 3 } & Bureau of statistic & &
\end{tabular}

\section{REVIEWED METHODOLOGY}

Availability of reliable power supply with considerable access to electricity is going to be the major the benchmark for evaluating the performance of the power sectors in the two countries. The performance of the reforms and policies in India and Nigeria are examined according to: i) The renewable and renewable energy sources. This sources include fossil fuels (Coal, oil and natural gas), hydro, solar and wind.

ii) Power generation capacities. This refers to the total power generation capacity of the two countries

iii) Power transmission capacities and losses. Transmission and distribution (T\&D) losses are estimated from the discrepancy between power produced and power sold to the customers assuming no theft of utility occurs.

iv) Electric power consumption (kWh per capita). This measures the production of power plants and combined heat and power plants less transmission, distribution, and transformation losses and own use by heat and power plants (World Bank, 2011).

v) Energy efficiency and renewable energy policies. These are policies that promote energy management and effective use of renewable energy sources like solar, wind and biomass.

vi) Energy sustainability index. Energy sustainability index published by the World Energy Council compares energy sustainability policies and prospects in many countries. The Index ranks countries according to their capability to provide sustainable energy policies using 3 dimensions of energy dilemma:

- Energy security: refers to the effective management of primary energy supply, the ability of participating energy companies to meet current and future demand and the reliability of energy infrastructure 
- Energy equity: deals with accessibility and affordability of energy supply in the country.

- Environmental sustainability: is concerned with the development of energy supply from renewable sources and the achievement of supply and demand-side energy efficiencies.

Countries are awarded a balance score which ranges from A - D for the three competing dimensions of energy dilemma. The balance score demonstrates how well a country manages the trade-offs between the three dimensions. Countries that perform high receive the score AAA while those that do not perform well receive a DDD score.

\section{Performance analysis}

Sources of power generation

India on the other hand has been reported to have 5.48 billion barrels of proven crude oil and 43.8 trillion cubic feet of natural gas reserves at the end of 2012. The country's western offshore holds majority of the reserves and the remaining are in the eastern regions of the country. It was the third largest producer of coal in the world in 2011 and holds the fifth largest coal reserves estimated to be 60.6 billion tons in the world (WEC, 2013). India's deposits of hard coal are located in the eastern part of the country. Eastern states of Chhattisgarh, Jharkhand and Orissa together account for about $64 \%$ of India's total coal reserves (EIA, 2014)
The north and north-eastern states of the country are rich in hydropower resources with significant river systems which benefit from energy surpluses in the monsoon period helping the country attain its targets in renewable energy generation (Raj and Ram, 2012). Himalayan rivers, Himachal Pradesh, Jammu and Kashmir and Uttarakhand hold 65 percent of India's small hydropower resources with lowest generation costs. Large hydro power potential in India is estimated at $148 \mathrm{GW}$ but only about $40 \mathrm{GW}$ out of the total potential capacity has so far been utilized for power generation in the country (Purohit et al. 2013). Similarly Nigeria, which has tropical climate is blessed with considerable reserves of fossil fuels more especially crude oil and natural gas. According to the US Energy Information Administration, Nigeria is the largest oil and natural gas producer in Africa. It is the ninth largest reserves holder of natural gas in the world

and holds the largest natural gas reserves in Africa (WEC, 2013). The country also has abundant renewable energy sources like hydro, wind, solar and biomass mostly found in the northern part of the country. There are over 278 unexploited small hydro sites with total potentials of 3,500 MW but so far less than 30 MW has been utilized (Shaaban and Petirin, 2014).

Table 2. Fossil fuel reserves in India and Nigeria in 2011

\begin{tabular}{|cccc|}
\hline Resource type & Total (Global) & India & Nigeria \\
\cline { 3 - 4 } Crude oil (Million tons) & 179,682 & $0.4 \%$ & $2.8 \%$ \\
Natural gas (Mtoe) & 209,741 & $0.5 \%$ & $2.4 \%$ \\
Coal (Mtoe) & & & $0.02 \%$ \\
\hline
\end{tabular}

\section{SOURCES WORLD ENERGY}

India has good solar radiation within a range of $4-7$ $\mathrm{kWh} / \mathrm{m} 2 /$ day with 250-300 sunny days in a year and an annual average wind speed of $3-6 \mathrm{~m} / \mathrm{s}$. Nigeria also has solar radiation with a range of $2-7 \mathrm{kWh} / \mathrm{m} 2 /$ day and an annual average wind speed of $2-4 \mathrm{~m} / \mathrm{s}$ (Agbetuyiet al. 2012)

4.2 Power generation capacities Power generation using fossil fuels is growing rapidly in India, primarily due to the government's efforts to improve the power supply to meet the growing demand. India is witnessing a remarkable growth in its power

generation sector due to effective government policies like the Mega Power Policy, Electricity Act 2003, National tariff policy 2006, National Rural Electrification Policies 2006 and the feed-in tariffs policy. The most successful policy that hugely transformed the Indian power sector is the Electricity Act 2003 (Sharma et al. 2013). The most conspicuous features of the Electricity Act 2003 are as follows (Singh and Srivastava,2004):

- Assigned SERCs and CERC as being responsible for licensing, tariff setting, grid rules and access rules
- Techno-economic clearance and state licensing for generating stations were abolished,

- Provided open access to transmission networks by all distribution companies without any discrimination

- Contributed to transparent power trading and creation of a spot market

- Called for gradual reduction of subsidies by the government

- Stipulated mandatory metering for all consumers to enhance accountability

- Provided special provisions for economically weaker people and promoted access to electricity in rural communities

- Had provisions for transition from a government-owned monopoly to a privately-owned and competitive industry - Created an efficient and dependable national transmission grid for optimum scheduling and dispatch of electricity among the regional transmission grids. The private sector is encouraged to participate meaningfully in the Indian power sector after the enactment of the Electricity Act 2003. Percentage contribution of the various sectors in hydro power generation in India is shown in Figure 1. 


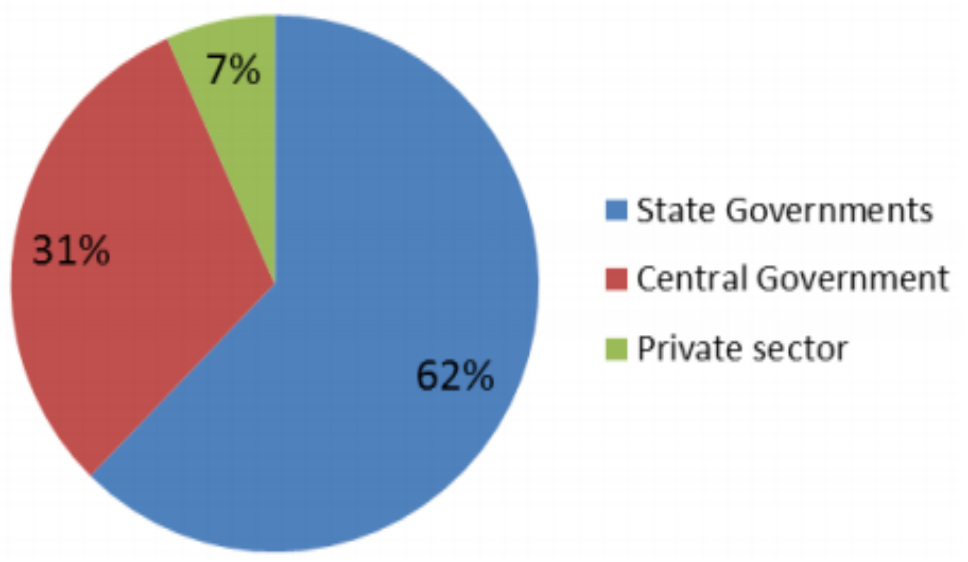

Figure 1. Sector wise installed hydro capacity in India (Sharma et al. 2013)

Figure 1 indicates that state governments in India have the largest share of installed hydro generation capacity compared to both the central government and the private sector.
The mega power policy is also having great impact in the Indian thermal generation sector as it encourages the private sector participation in the construction of mega power plants. In 2014 thermal power contributed $163.3 \mathrm{GW}$ out of the $237 \mathrm{GW}$ total generation capacity in India.

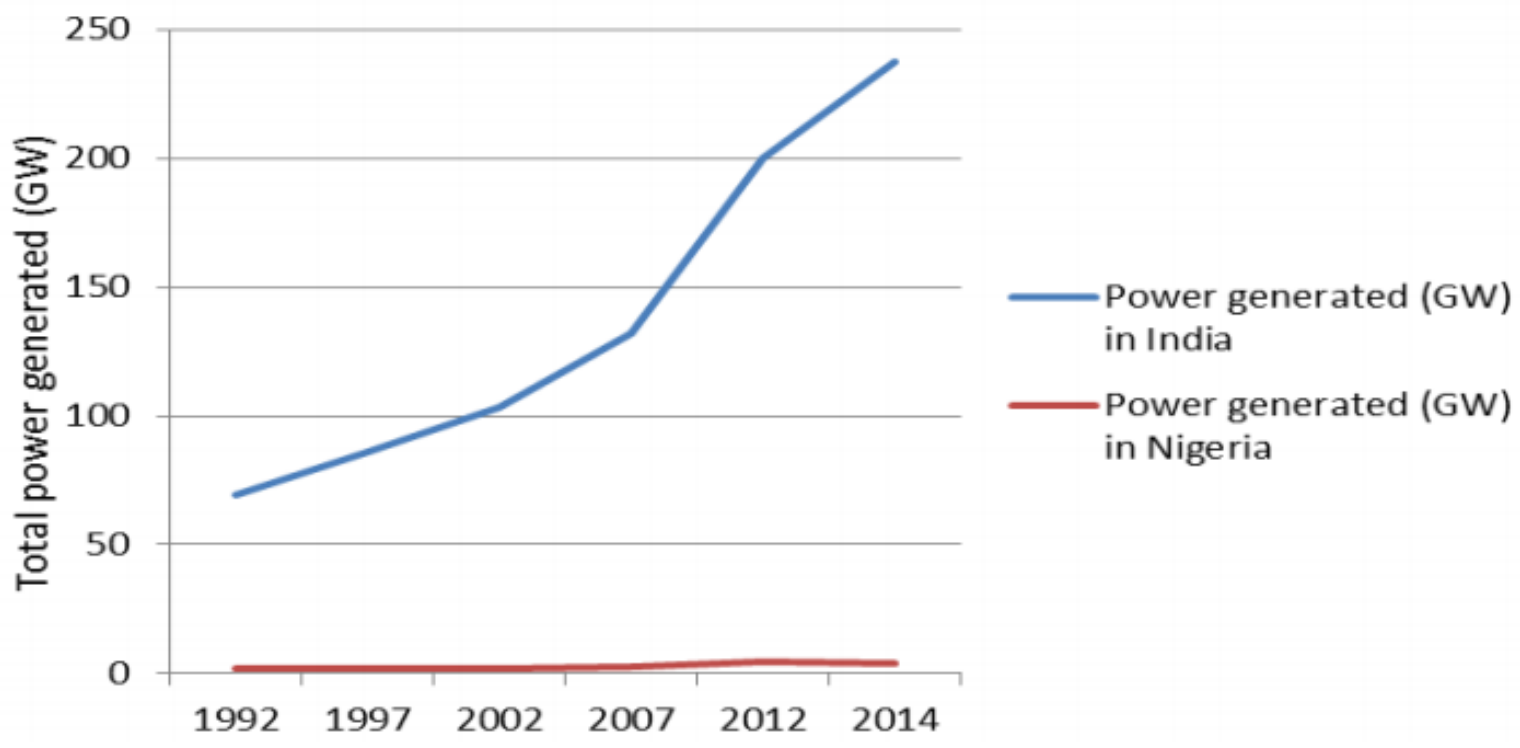

Figure 2. Growth of power generation sectors in India and Nigeria.

Figure 3 indicates that the Indian generation sector witnessed a surge in capacity from 2003 to 2014

with more pronounce growth recorded between 2007 and 2012. Nigeria on the hand witnessed very little additional capacity between 1992 and 2014. The highest peak power generated in the country was $4.5 \mathrm{GW}$ in
December 2012. Existing thermal power plants in Nigeria contributed about $72 \%$ of the total $3.7 \mathrm{GW}$ of electricity generated in 2014 (MOP, 2014). Despite contributing the highest share in the generation mix, majority of thermal plants in Nigeria operate below $50 \%$ of their installed capacity (Aliyu et al. 2013). 


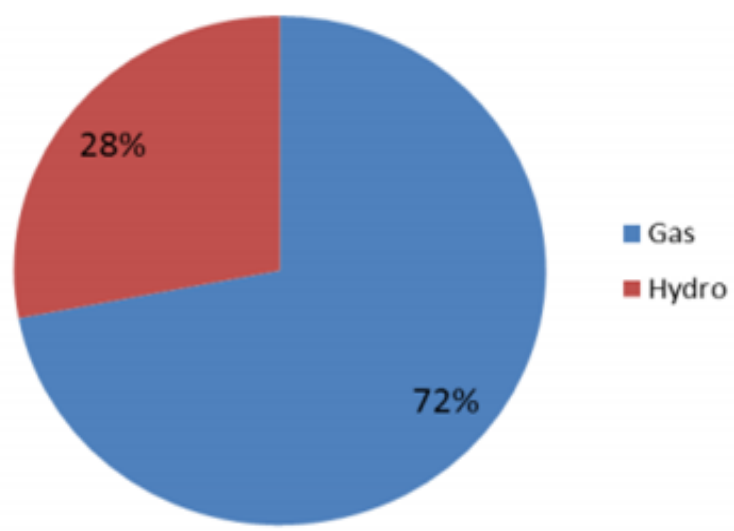

Figure 3.Power Generation mix for Nigeria 2014

Figure 3 indicates that thermal power plants contribute about $72 \%$ of the total power generated. The three existing hydroelectric dams in the country (Kainji, Shiroro and Jebba) contributed the remaining $28 \%$ of the power generated to the national grid during the same period. Currently there is no grid connected renewable energy generating plant in Nigeria despite the abundant renewable energy sources in the country. The $10 \mathrm{MW}$ Katsina wind farm which is the first renewable energy generating plant initiated by the government in 2009 (Oji et al. 2012). The $10 \mathrm{MW}$ wind farm is still not completed due to inadequate funding by the government.

4.3 Power transmission capacities and losses.

Transmission lines in India are divided into $765 \mathrm{kV}$ lines which have a total length of $32,250 \mathrm{~km}, 400 \mathrm{kV}$ with $144,819 \mathrm{~km}$ and $220 \mathrm{kV}$ transmission lines having a total length of $170,980 \mathrm{~km}$. The country's transmission and distribution (T \& D) losses vary from state to state with some states having losses as high as $33 \%$ while others have losses around $25 \%$. The average $\mathrm{T} \& \mathrm{D}$ losses in the country currently stand at $23.6 \%$ (CEA, 2013).

On the other hand high voltage transmission lines in Nigeria are made up of $132 \mathrm{kV}$ and $330 \mathrm{kV}$ transmission lines. The $330 \mathrm{kV}$ lines have a total length of 5,650 $\mathrm{km}$ while the $132 \mathrm{kV}$ lines have $6,687 \mathrm{~km}$ making a total of 12,337 km (NDPHC, 2014). Nigeria's T \& D losses were rated as one of the highest in Africa with losses reaching up to $35 \%$ in 2013 due to the poor state of the power sector (Shaaban and Petirin, 2014).

4.4 Electric power consumption (kWh per capita)

This measures the average electricity use per capita in a country for a specified period which is usually one year. The electricity consumption per capita in India and Nigeria for 2011 is shown in Table 4.

Table 4 Electricity consumption per capita for India and Nigeria (World Bank, 2013)

\begin{tabular}{|c|c|}
\hline Country & Electric power consumption per capita (kWh/year) \\
\hline India & 684 \\
\hline Nigeria & 149 \\
\hline
\end{tabular}

Nigeria's electricity consumption per capita in Table 4 implies that its population does not have access to reliable electricity supply. The country's electricity consumption per capita is one of the lowest in the world.

4.5 Energy efficiency and renewable energy policies
Energy efficiency policies and laws are adopted as a means to improve power sector performance. Table 5 below lists the energy efficiency policies in India and Nigeria. These laws and policies are necessary in order to minimize greenhouse gas emissions and improve the reliability of electricity supply. Table 5 Energy efficiency policies and laws in India and Nigeria (WEC, 2014)

Table 5. Energy policies in India and Nigeria

\begin{tabular}{lcc}
\hline Energy efficiency policies and programs & India & Nigeria \\
\hline National energy agency & \\
Ministry or department for energy efficiency & \\
Local/regional energy agencies & \\
Dedicated energy efficiency fund & \\
Energy efficiency law & \\
Energy efficiency law with targets & - Not available
\end{tabular}


Table 5 indicates that India has more energy efficiency policies and laws compared to Nigeria. The Indian government also established the national mission on enhanced energy efficiency as an initiative aimed at addressing national problems of inefficient energy use. The mission introduced an innovative mechanism called
"Perform, Achieve and Trade" (PAT) mechanism which assigns energy efficiency improvement targets to India's most energy intensive industries (WEC, 2014). Despite having more challenges in its power sector, Nigeria still lags behind India in the promotion and implementation of energy efficiency policies to manage the little power produced.

\subsection{Energy sustainability index}

Table 6 Comparison of Energy trilemma scores of India and Nigeria (WEC, 2014)
\begin{tabular}{cllll} 
Country & $\begin{array}{l}\text { Energy } \\
\text { Security }\end{array}$ & $\begin{array}{l}\text { Energy } \\
\text { equity }\end{array}$ & $\begin{array}{l}\text { Environmental } \\
\text { sustainability }\end{array}$ & Score \\
\hline India & C & D & D & CDD
\end{tabular}
Nigeria
A
D
C
ADC

Table 6 indicates that Nigeria performs better in energy security and environmental sustainability due to higher natural gas reserves and lower carbon emission from its power generation sector compared India. Nigeria's weakest performance is in the energy equity which is largely due to its inability to provide reliable power supply to majority of its population. Nigeria ranked $81^{\text {st }}$ in the 2014 global ranking for dilemma index and balanced scores. While India's lowest performance comes from the energy equity and environmental sustainability dimensions which eventually placed it in 122nd position in the 2014 global ranking for trilemma index and balanced scores (WEC, 2014).

\section{CONCLUSION}

Nigerians have been experiencing chronic power shortages despite several reforms implemented by the government. The challenges experienced before the enactment of the ESPR Act 2005 still exist in the power sector despite the huge investments and reforms implemented to improve the performance of the sector.The average power generated by all the country's power plants was about 3.7 GW in 2014 which is grossly inadequate for Nigeria's population of about 177 million. Major factors that inhibit the development of Nigerian power sector are inconsistency in the implementation of government policies and corruption. On the other hand, India's power sector witnessed massive transformation after the enactment of the Electricity Act 2003. The Electricity Act opened up the generation and the distribution sectors for private sector participation. The mega power policy and the renewable energy policies like the feed-in tariffs have contributed immensely to the growth and development of the Indian power sector. The country's generation capacity was about $100 \mathrm{GW}$ in 2002 which rapidly rose to about $237 \mathrm{GW}$ in 2014. Although its transmission sector is also witnessing remarkable improvements with the adoption of higher transmission voltages up to $765 \mathrm{kV}$, still its transmission and distribution losses are among the highest in the world. The country has been taking drastic measures to curb the inefficiencies in the in its power sector by promoting renewable energy generation and energy efficiency policies and laws like the "perform, achieve and trade" mechanism.

\section{REFERENCES}

[1] Babanyara, Y.Y and U. F. Saleh (2010), Urbanisation and the choice of fuel wood as a Source of Energy in Nigeria .Journal of Human Ecology, vol. 31 pp: 19-26

[2] Bajaj, L. H, Sharma D. (2006). Power Sector Reforms in India International conference on power electronics, drives and energy systems, Indian Institute of Technology, New Delhi. 12 - 15 December 2006, New Delhi. pp: 1 - 5. CEA (2014). CEA (2013).

[3] Central Electricity Authority of India's annual status report on power sector development in India, Feb. 2014. Viewed at: http://cea.nic.in/reports/monthly/executive_rep/oct13.pdf

[4] EIA (2014). United States Energy Information Administration, Viewed 15 Dec. 2014, at http://www.eia.gov/countries/cab.cfm?fips=ni

[5] Ekeh J.C (2008), Issues and Challenges of Power Sector Reforms in a Depressed Economy, 5th international conference on European Electricity Market, Instituto Superior de Engenharia de Lisboa, 28 - 30 May, 2008, Lisbon, IEEE pp: 1 - 7.

[6] Energy Commission of Nigeria (2008), Assessment of Energy Options and Strategies for Nigeria: Energy Demand, Supply and Environmental Analysis for Sustainable Energy Development (2000-2030). Report No. ECN/EPA/2008/01.

[7] Gatugel Z. U., Abbasoglu S. (2014). An overview of power sector laws, policies and reforms in Nigeria. Asian. Transactions Journal of Engineering. Vol. 4(2) pp. 6 - 12 IMF (2014). World economic outlook database. Viewed 20 Apr. 2015 at http://www.imf.org/external/pubs/ft/weo/2015/01/weodata/weosel gr.aspx 